\title{
Gemcitabine-induced Hemolytic Uremic Syndrome Mimicking Scleroderma Renal Crisis Presenting with Raynaud's Phenomenon, Positive Antinuclear Antibodies and Hypertensive Emergency
}

\author{
Yuichiro Yamada, Keisuke Suzuki, Hironobu Nobata, Hirohisa Kawai, Ryo Wakamatsu, \\ Naoto Miura, Shogo Banno and Hirokazu Imai
}

\begin{abstract}
A 58-year-old woman who received gemcitabine for advanced gallbladder cancer developed an impaired renal function, thrombocytopenia, Raynaud's phenomenon, digital ischemic changes, a high antinuclear antibody titer and hypertensive emergency that mimicked a scleroderma renal crisis. A kidney biopsy specimen demonstrated onion-skin lesions in the arterioles and small arteries along with ischemic changes in the glomeruli, compatible with a diagnosis of hypertensive emergency (malignant hypertension). The intravenous administration of a calcium channel blocker, the oral administration of an angiotensin-converting enzyme inhibitor and angiotensin II receptor blocker and the transfusion of fresh frozen plasma were effective for treating the thrombocytopenia and progressive kidney dysfunction. Gemcitabine induces hemolytic uremic syndrome with accelerated hypertension and Raynaud's phenomenon, mimicking scleroderma renal crisis.
\end{abstract}

Key words: gemcitabine, antinuclear antibody, Raynaud's phenomenon, hemolytic uremic syndrome, hypertensive emergency, fresh frozen plasma

(Intern Med 53: 445-448, 2014)

(DOI: 10.2169/internalmedicine.53.1160)

\section{Introduction}

Gemcitabine, a new nucleoside analogue used to treat non-small cell lung cancer, pancreatic adenocarcinoma, ovarian tumors and gallbladder cancer (1-3) has been reported to cause hemolytic uremic syndrome (HUS) (4-14), a type of thrombotic microangiopathy characterized by an impaired renal function, thrombocytopenia and hemolytic anemia with fragmented red cells (15). HUS is divided into two types. One type involves damaged endothelial cells due to Shigalike toxin and is primarily observed in children (diarrheapositive HUS: $\left(\mathrm{D}^{+}\right)$HUS). The other form, which is primarily observed in adults, is due to other chemicals or systemic diseases (diarrhea-negative HUS: (D) HUS). In the present patient, HUS was induced by gemcitabine, with a presentation mimicking scleroderma renal crisis that included Raynaud's phenomenon with swollen fingers, digital ischemic changes, a positive antinuclear antibody titer and hypertensive emergency, also known as malignant hypertension.

\section{Case Report}

A 58-year-old woman was admitted to Aichi Medical University Hospital due to an impaired renal function, thrombocytopenia and hypertensive emergency. She had undergone surgery for gallbladder cancer 15 months prior to admission. One month after the surgery, the patient began to take oral TS-1, a combination of tegafur and gimeracil, for six months. Gemcitabine was administered from eight months to one month prior to admission. After starting gemcitabine, the patient began to experience Raynaud's phenomenon with swollen fingers. She felt severe pain in the fingertips of both hands, which had a blue color. The serum creatinine level increased from $0.65 \mathrm{mg} / \mathrm{dL}$ at four months prior to admission to $2.50 \mathrm{mg} / \mathrm{dL}$ at three months prior to 
admission. One month prior to admission, the patient was diagnosed with proteinuria, hematuria and rapidly progressive hypertension. She underwent a kidney biopsy at the former hospital and was then transferred to our hospital due to an impaired renal function, thrombocytopenia and hypertensive emergency.

On admission, the patient's mental status was normal, her height was $158 \mathrm{~cm}$ and her weight was $60 \mathrm{~kg}$. Her body temperature was $35.8^{\circ} \mathrm{C}$, her pulse was 60 beats/min and regular, her respiratory rate was 20 breaths/min and her blood pressure was $212 / 120 \mathrm{mmHg}$. A physical examination revealed a red left eye, audible coarse crackles in both lower lung fields and lower extremity edema. A fundoscopic examination demonstrated flame-shaped areas of hemorrhage and soft exudates with papilledema. Laboratory studies indicated $2^{+}$proteinuria $\left(3.5 \mathrm{~g} / \mathrm{g}\right.$ creatinine), $2^{+}$urine occult blood with 1-4 red blood cells (RBCs) per high-power field, a white blood cell count of 155,00, a RBC count of $320 \times$ $10^{4} / \mu \mathrm{L}$ with six fragmented red cells per $1,000 \mathrm{RBCs}$, a hemoglobin level of $10.0 \mathrm{~g} / \mathrm{L}$, a hematocrit level of $31.8 \%$, a platelet count of $6.9 \times 10^{4} / \mu \mathrm{L}$, an albumin level of $3.2 \mathrm{~g} / \mathrm{dL}$, a blood urea nitrogen level of $53.7 \mathrm{mg} / \mathrm{dL}$, a serum creatinine level of $2.57 \mathrm{mg} / \mathrm{dL}$ and a total cholesterol level of $246 \mathrm{mg} /$ $\mathrm{dL}$. The haptoglobin level was below $10 \mathrm{mg} / \mathrm{dL}$. The levels of direct and indirect bilirubin were $0.45 \mathrm{mg} / \mathrm{dL}$ and 2.01 $\mathrm{mg} / \mathrm{dL}$, respectively. The $\mathrm{Na}$ level was $138 \mathrm{mmol} / \mathrm{L}$, the $\mathrm{K}$ level was $5.0 \mathrm{mmol} / \mathrm{L}$, the $\mathrm{Cl}$ level was $104 \mathrm{mmol} / \mathrm{L}$, the AST level was $39 \mathrm{U} / \mathrm{L}$ and the ALT level was $24 \mathrm{U} / \mathrm{L}$. The lactate dehydrogenase level was $636 \mathrm{IU} / \mathrm{L}$, the CK level was $157 \mathrm{IU} / \mathrm{L}$ and the total bilirubin, direct bilirubin and indirect bilirubin levels were $2.46,0.45$ and $2.01 \mathrm{mg} / \mathrm{dL}$, respectively. The CRP level was $0.10 \mathrm{mg} / \mathrm{dL}$. The PT-INR was 1.02, the APTT was 24.3 seconds, the fibrinogen level was $146 \mathrm{mg} / \mathrm{dL}$, the FDP-DD was 3.46 and the ATIII was $110 \%$. Antinuclear antibodies were positive at 1:1,280 in a speckled pattern. Anti-sclero70, anti-centromere and anti-RNP antibodies were all negative. Rheumatoid factor, hepatitis B antigens, hepatitis $\mathrm{C}$ virus antibodies and other autoantibodies were also negative. A few days later, the following results became available: plasma rennin activity $=2.1 \mathrm{ng} / \mathrm{mL} / \mathrm{h}$ (normal range: $(0.3-2.9 \mathrm{ng} / \mathrm{mL} / \mathrm{h})$, plasma aldosterone $=58.7$ $\mathrm{pg} / \mathrm{mL}$ (normal range: $30-160 \mathrm{pg} / \mathrm{mL}$ ), adrenaline $=96 \mathrm{pg} / \mathrm{mL}$ (normal range: $<100 \mathrm{pg} / \mathrm{mL}$ ), noradrenaline $=927 \mathrm{pg} / \mathrm{mL}$ (normal range: $100-450 \mathrm{pg} / \mathrm{mL}$ ) and dopamine $=25 \mathrm{pg} / \mathrm{mL}$ (normal range: $<20 \mathrm{pg} / \mathrm{mL}$ ).

A plain chest X-ray demonstrated an enlargement of the cardiac silhouette, with a cardiothoracic ratio of 0.585 . Echocardiography revealed mild MR and mild TR. An ECG showed no abnormal findings.

A chest CT scan demonstrated a mild degree of interstitial pneumonia in both lower lung fields and a mild degree of pleural effusion bilaterally. An abdominal CT scan showed a hemangioma with a diameter of $2.0 \mathrm{~cm}$ in the spleen.

In the kidney biopsy specimen, four of the 20 obtained glomeruli showed global sclerosis, while the remaining glomeruli exhibited ischemic changes, such as irregular basement membranes in the capillary loop and Bowman's capsule (Figure A). Segmental mesangial cell proliferation with an increased mesangial matrix and double contours of the basement membrane in parts of the capillary loop were observed (Figure B). The small arteries were occluded by an increased number of intimal cells and a homogenous substance in the subendothelial spaces. There were numerous mononuclear cells around the small arteries (Figure C). The basement membranes of the small arteries were obliterated and the lumens of the arteries were narrowed by a vacuolated substance in the subendothelial spaces and an increased number of intimal cells. Onion-skin lesions were observed in the arterioles. A moderate degree of interstitial fibrosis was observed (Figure D). These findings are compatible with a diagnosis of hypertensive emergency, also known as malignant hypertension.

\section{Clinical course}

Starting on the first day of admission, $450 \mathrm{~mL}$ of fresh frozen plasma was administered for three days to treat thrombotic microangiopathy. An intravenous calcium channel blocker with an oral angiotensin-converting enzyme inhibitor (ACE-I) and angiotensin II receptor blocker (ARB) were used to treat malignant hypertension. The platelet count recovered from $6.5 \times 10^{4} / \mu \mathrm{L}$ at admission to $12.7 \times 10^{4} /$ $\mu \mathrm{L}$ on the fifth hospital day. However, the serum creatinine level increased from $2.57 \mathrm{mg} / \mathrm{dL}$ to $3.48 \mathrm{mg} / \mathrm{dL}$ on the fifth hospital day. She was discharged with a platelet count of $10.0 \times 10^{4} / \mu \mathrm{L}$ and a serum creatinine level of $4.61 \mathrm{mg} / \mathrm{dL}$ on the 20th hospital day.

Two months later, the patient was diagnosed with worsening pleural effusion and ascites due to metastatic peritonitis at the former hospital. She was treated with diuretics. Fifteen months after the present episode, her platelet count was $21.1 \times 10^{4} / \mu \mathrm{L}$ and her serum creatinine level was $2.64 \mathrm{mg} / \mathrm{dL}$ while not taking the ACE-I and ARB, despite the presence of multiple liver metastases.

\section{Discussion}

There are two unique aspects to the present case. The first is the resemblance of the presentation to scleroderma renal crisis, including findings such as Raynaud's phenomenon with swollen fingers, digital ischemic changes, thrombocytopenia with fragmented red blood cells, a positive antinuclear antibody titer at 1:1,280 dilution and hypertensive emergency. The second is that the impaired renal function and thrombocytopenia resolved following the administration of antihypertensive drugs and fresh frozen plasma as well as the discontinuation of gemcitabine. On admission, we initially made a diagnosis of scleroderma renal crisis before recognizing the relationship between gemcitabine and HUS.

Gemcitabine-induced HUS (GIHUS) was first reported by Brodowicz et al. in 1997 (4). In 1999, Fung et al. reported a crude incidence rate of $0.015 \%$ (range, 0.008-0.078\%), based on 78,800 patient exposures, according to the manu- 


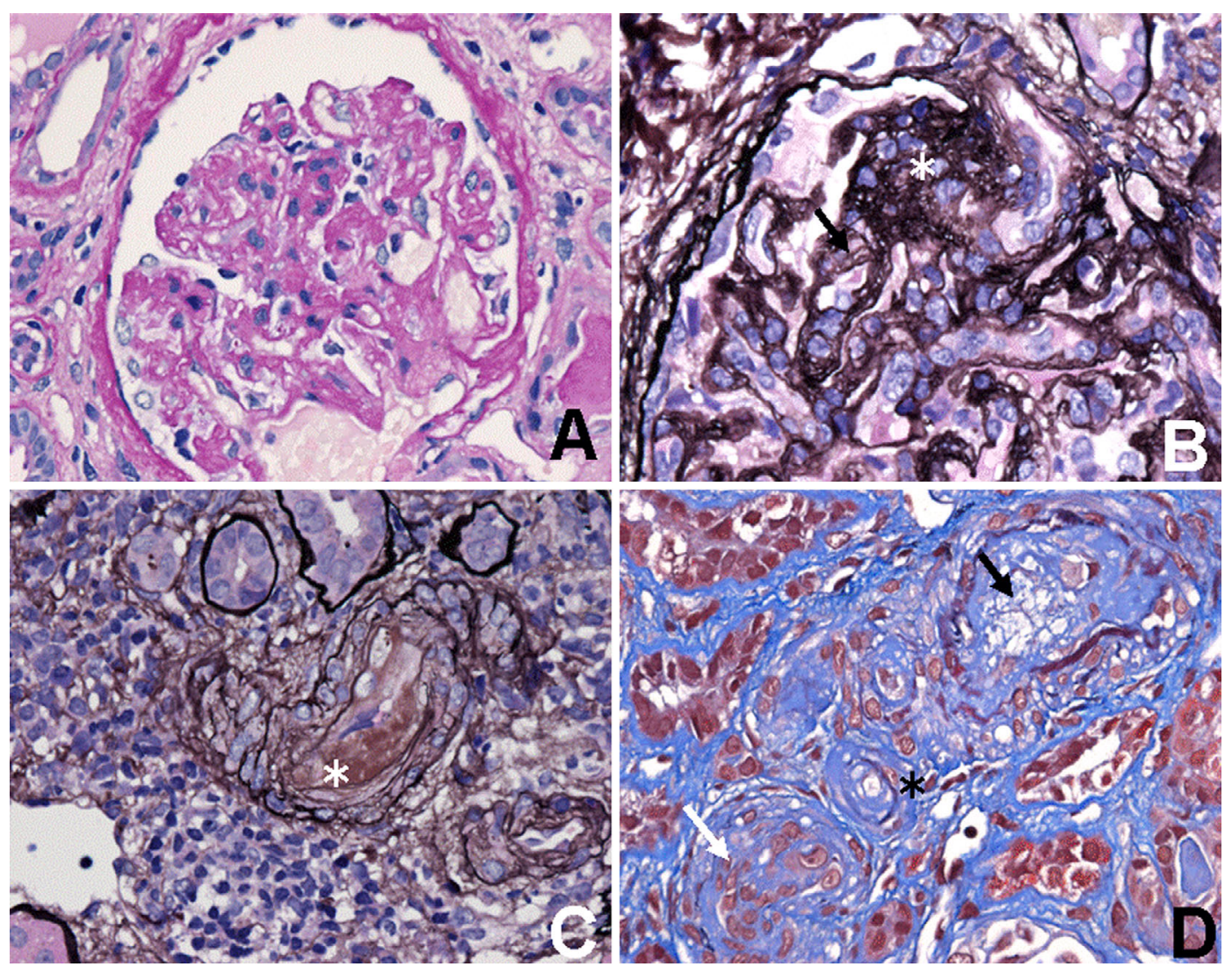

Figure. Pathological findings of the kidney biopsy specimen. A: The glomerulus shows ischemic changes, such as shrinking capillary loops without mesangial proliferation (Hematoxylin and Eosin staining, $\times 200)$. B: Another glomerulus shows segmental mesangial cell proliferation with an increased mesangial matrix (asterisk) and increased cells in the capillary lumen. Double contours were observed in part of the capillary loops (arrow) (PAMS stain, $\times 400$ ). C: A small artery is occluded by increased intimal cells and a homogenous substance in the subendothelial spaces (asterisk). Numerous mononuclear cells were present around the small arteries (PAMS stain, $\times 400$ ). D: The basement membranes of the small arteries were destroyed and the luminal space of the arteries was narrowed due to the presence of an increased vacuolated substance in the subendothelial spaces (black arrow) and increased intimal cells (white arrow). The arteriole shows onion-skin lesions (asterisk). A moderate degree of interstitial fibrosis was observed (Elastica Masson stain, $\times 400$ ).

facturer's database of adverse events (6). It has been reported that GIHUS occurs in approximately $0.2-0.4 \%$ of patients who receive gemcitabine $(9,11)$. The incidence of HUS induced by gemcitabine is significantly lower than the incidence of HUS associated with mitomycin C (2$15 \%$ ) (16). However, the relatively high frequency of an impaired renal function associated with gemcitabine suggests that the frequency of GIHUS may be underestimated due to the lack of medical awareness.

Regarding the skin manifestations of GIHUS, aggravation of digital necrosis following the administration of gemcitabine and other antitumor drugs has been reported in patients with systemic sclerosis (17-19). Bassis et al. first demonstrated gemcitabine-induced scleroderma-like skin changes in a patient who previously had no signs of scleroderma (20). The patient in this case also had new-onset Raynaud's phenomenon with swollen fingers following the administration of gemcitabine; however, we were unable to identify whether the antinuclear antibody titer became posi- tive before or after the administration of gemcitabine. One possibility is that the present patient already had antinuclear antibodies before exhibiting Raynaud's phenomenon. Livedo reticularis and panniculitis have also been reported to be initial manifestations $(21,22)$, while endothelial damage and fat cell necrosis caused by gemcitabine have been observed in pathological analyses. These findings suggest that scleroderma or other autoimmune diseases are risk factors for GIHUS or that gemcitabine itself aggravates scleroderma. Humphreys et al. (9) demonstrated that the median time to development of HUS following the initiation of gemcitabine is eight months (range, 3-18 months). In that study, seven of nine patients developed new-onset or exacerbated hypertension. In the present case, gemcitabine was started in August, and the patient recognized Raynaud's phenomenon with swollen fingers in November. Although cold temperatures can influence the occurrence of SRC or malignant hypertension, gemcitabine-induced endothelial damage is the primary cause of digital ischemic changes. 
In order to treat GIHUS, discontinuing gemcitabine is essential. Other therapies, such as antihypertensive drugs, plasma exchange and dialysis, have been proposed. Initially, we thought that hypertensive emergency induced by scleroderma was the primary event in this patient; therefore, antihypertensive drugs, including an intravenous calcium channel blocker, oral ACE-I and oral ARB were started. In addition, we administered fresh frozen plasma because a decreased level of ADAMTS13 was suspected due to endothelial damage. An extensive review of the literature showed that the present case represents the typical clinical course of GIHUS and that the most important treatment is the discontinuation of gemcitabine; therapeutic plasma exchange is less effective. In the present patient, the clinical signs and laboratory data gradually normalized after treatment.

Recently, the occurrence of atypical HUS related to abnormal complement factor $\mathrm{H}$ was reported. Whether GIHUS depends on abnormal complement factor $\mathrm{H}$ is an important issue, although we were unable to analyze the serum level of complement factor $\mathrm{H}$ in this case.

Regarding the prognosis of GIHUS, no patients have died as a direct result of TMA. A quarter of the reported patients developed renal failure requiring dialysis, while one patient developed chronic kidney insufficiency $(9,14)$. It is very important to stop the administration of gemcitabine in order to prevent progressive renal failure when Raynaud's phenomenon, urinary abnormalities or hypertension appear after the use of gemcitabine.

Gemcitabine is used worldwide to safely and efficaciously treat advanced cancer; however, physicians should be aware of the possibility of GIHUS, especially in patients with scleroderma or other autoimmune diseases.

The authors state that they have no Conflict of Interest (COI).

\section{References}

1. Carmichael J. The role of gemcitabine in the treatment of other tumours. Br J Cancer 78: 21-25, 1998.

2. Moore MJ, Tannock IF, Ernst DS, Huan S, Murray N. Gemcitabine: a promising new agent in the treatment of advanced urothelial cancer. J Clin Oncol 15: 3441-3445, 1977.

3. Sternberg CN. Gemcitabine in bladder cancer. Semin Oncol 27: 31-39, 2000.

4. Brodowicz T, Breiteneder S, Wiltschke C, Zielinski CC Gemcitabine-induced hemolytic uremic syndrome: a case report. J Natl Cancer Inst 89: 1895-1896, 1997.
5. Choi M, Woywodt A, Göbel U, Schneider W, Kettritz R. Haemolytic uraemic syndrome after gemcitabine treatment for pancreatic carcinoma. Nephrol Dial Transplant 14: 2523-2524, 1999.

6. Fung MC, Storniolo AM, Nguyen B, Arning M, Brookfield W, Vigil J. A review of hemolytic uremic syndrome in patients treated with gemcitabine therapy. Cancer 85: 2023-2032, 1999.

7. Walter RB, Joerger M, Pestalozzi BC. Gemcitabine-associated hemolytic-uremic syndrome. Am J Kidney Dis 40: E16, 2002.

8. Müller S, Schütt $\mathrm{P}$, Bojko $\mathrm{P}$, et al. Hemolytic uremic syndrome following prolonged gemcitabine therapy: report of four cases from a single institution. Ann Hematol 84: 110-114, 2005.

9. Humphreys BD, Sharman JP, Henderson JM, et al. Gemcitabineassociated thrombotic microangiopathy. Cancer 100: 2664-2670, 2004.

10. Saif MW, McGee PJ. Hemolytic-uremic syndrome associated with gemcitabine: a case report and review of literature. JOP 6: 369374, 2005

11. Izzedine $H$, Isnard-Bagnis $C$, Launay-Vacher $V$, et al. Gemcitabine-induced thrombotic microangiopathy: a systematic review. Nephrol Dial Transplant 21: 3038-3045, 2006.

12. Kalra N, Kad R, Osama S. Gemcitabine-induced hemolytic uremic syndrome in ovarian carcinoma. Int $\mathrm{J}$ Clin Oncol 12: 385-387, 2007.

13. Boeck S, Geiger S, Schulz C, Heinemann V. Hemolytic-uremic syndrome associated with gemcitabine treatment for metastatic pancreatic cancer. J Clin Gastroenterol 42: 551-552, 2008.

14. Gore EM, Jones BS, Marques MB. Is therapeutic plasma exchange indicated for patients with gemcitabine-induced hemolytic uremic syndrome? J Clin Apher 24: 209-214, 2009.

15. Moake JL. Thrombotic microangiopathies. N Engl J Med 347: 589-600, 2002.

16. Blake-Haskins JA, Lechleider RJ, Kreitman RJ. Thrombotic microangiopathy with targeted cancer agents. Clin Cancer Res 17: 5858-5866, 2011.

17. Clowse MEB, Wigley FM. Digital necrosis related to carboplatin and gemcitabine therapy in systemic sclerosis. J Rheumatol 30: 1341-1343, 2003.

18. Marie I, Levesque $H$, Plissonnier D, Balguerie $X$, Cailleux N, Courtois H. Digital necrosis related to cisplatin in systemic sclerosis. Br J Dermatol 142: 833-834, 2000.

19. Zaima $C$, Kanai $M$, Ishikawa $S$, et al. A case of progressive digital ischemia after early withdrawal of gemcitabine and S-1 in a patient with systemic sclerosis. Jpn J Clin Oncol 41: 803-806, 2011.

20. Bessis D, Guillot B, Legouffe E, Guilhou JJ. Gemcitabineassociated scleroderma-like changes of the lower extremities. J Am Acad Dermatol 51 (2 Suppl): S73-S76, 2004.

21. Zemtsov A, Omueti-Ayoade K, Zemtsov R, Yang M. Livedo reticularis as an initial clinical manifestation of gemcitabine-induced hemolytic uremic syndrome. J Dermatol 39: 487-489, 2012.

22. Mir-Bonafé JM, Román-Curto C, Santos-Briz A, Cañueto J, Fernández-López E, Unamuno P. Gemcitabine-associated livedoid thrombotic microangiopathy with associated sclerema neonatorumlike microscopic changes. J Cutan Pathol 39: 707-711, 2012.

(C) 2014 The Japanese Society of Internal Medicine

http://www.naika.or.jp/imonline/index.html 